九州大学学術情報リポジトリ

Kyushu University Institutional Repository

Fabrication of Ultrananocrystalline

Diamond/Nonhydrogenated Amorphous Carbon

Composite Films for Hard Coating by Coaxial Arc Plasma Deposition

Naragino, Hiroshi

Department of Applied Science for Electronics and Materials, Kyushu University

Egiza, Mohamed

Department of Applied Science for Electronics and Materials, Kyushu University I Mechanical Engineering Department, Kafrelsheikh University

Tominaga, Aki

Department of Applied Science for Electronics and Materials, Kyushu University

Murasawa, Koki

OSG Corporation

他

https://doi.org/10.5109/1657379

出版情報: Evergreen. 3 (1)，pp. 1-5，2016-03. Green Asia Education Center バージョン：

権利関係 : 


\title{
Fabrication of Ultrananocrystalline Diamond/Nonhydrogenated Amorphous Carbon Composite Films for Hard Coating by Coaxial Arc Plasma Deposition
}

\author{
Hiroshi Naragino ${ }^{1, *}$, Mohamed Egiza1, ${ }^{1,}$, Aki Tominaga ${ }^{1}$, Koki Murasawa ${ }^{3}$, \\ Hidenobu Gonda ${ }^{3}$, Masatoshi Sakurai ${ }^{3}$, Tsuyoshi Yoshitake ${ }^{1, * *}$ \\ ${ }^{1}$ Dept. of Appl. Sci. for Electr. and Mat., Kyushu Univ., 6-1 Kasuga, Fukuoka 816-8580, Japan \\ ${ }^{2}$ Mechanical Engineering Department, Kafrelsheikh University, Kafrelsheikh, 33516, Egypt \\ ${ }^{3}$ OSG Corporation, 2-17 Shirakumo-cho, Toyokawa, Aichi 442-0018, Japan
}

Author to whom correspondence should be addressed,

*E-mail: hiroshi_naragino@kyudai.jp,**E-mail: tsuyoshi_yoshitake@kyudai.jp

(Received November 20, 2015; accepted December 18, 2015).

\begin{abstract}
Ultrananocrystalline diamond (UNCD)/nonhydrogenated amorphous carbon (a-C) composite (UNCD/a-C) films were deposited on cemented carbide (WC-Co) substrates by coaxial arc plasma deposition (CAPD). To suppress the graphitization induced by Co in the WC-Co, the film deposition was carried out on unheated substrates. The hardness and Young's modulus were $51.3 \mathrm{GPa}$ and 520.2 GPa, respectively. These values are comparable or rather larger than those of UNCD/a-C films deposited on other substrates such as $\mathrm{Si}$, which implies that the graphitization of UNCD/a-C hardly occurs. Surprisingly, UNCD/a-C films could be deposited at the maximum film thickness of approximately $3 \mu \mathrm{m}$ in spite of the room temperature growth. The internal compress-stress of the film is approximately $4.5 \mathrm{GPa}$, which is evidently smaller than that of comparably hard a-C films. The existence of a large number of grain boundaries in the films, which is structural specific to UNCD/a$\mathrm{C}$, might play an important role in the release of an internal stress in the film. It was experimentally demonstrated that UNCD/a-C films prepared by CAPD are potential hard coating materials for WCCo.
\end{abstract}

Keywords: nanocrystalline diamond, hard coating, coaxial arc plasma deposition, hardness, modules, internal stress

\section{Introduction}

Since diamond is the hardest substance in nature, it has attracted much attention as promising hard coating materials for cutting tools such as drill bits and end mills. Practically, polycrystalline diamond films have been deposited on cutting tools composed of cemented carbide (WC-Co) by chemical vapor deposition (CVD) ${ }^{1,2,3)}$. However, the CVD deposition of polycrystalline diamond films on WC-Co has the following requirements in the film deposition condition and disadvantages: i) cutting tool materials should be heatproof because the substrate temperature in CVD reaches $800-1000{ }^{\circ} \mathrm{C}$ during the deposition; ii) the pretreatment of substrates with diamond powder, so-called seeding, is required instead of the nucleation of diamond; and iii) generally, it takes more than 10 hours for the deposition of several-micrometers films due to a low deposition rate; iv) Co in WC-Co substrates should be removed by chemical etching prior to the deposition of diamond films [1-3], since Co acts as a catalyst that facilitates graphitization, which drastically degrades the quality of diamond films ${ }^{4,5}$. Naturally, the catalytic effect is enhanced with increasing substrate temperature during the deposition.

Hard amorphous carbon, so-called diamond-like carbon, have attracted attention as coating materials alternative to diamond ${ }^{6,7,8,9)}$. In particular, nonhydrogenated amorphous carbon (a-C) films deposited by filtered cathodic vacuum arc (FCVA $)^{8,9)}$ and sputtering ${ }^{6,7)}$ possess higher hardness than that of hydrogenated amorphous carbon (a-C:H) films prepared by CVD. Hard amorphous carbon films are deposited at low substrate temperatures, and a-C films can be deposited at lower substrate temperatures than a-C:H films prepared by CVD. However, even for the deposition of a-C films, the catalytic effects of Co in WC-Co cannot be negligible. For instance, it has been reported that the temperature of a substrate set on a copper cooling block increases up to $75^{\circ} \mathrm{C}$ during the film deposition by FCVA ${ }^{9)}$, and it induces the graphitization of a-C films due to the catalytic effects of $\mathrm{Co}^{10}$. Of course, the hardness of the a-C films is drastically decreased ${ }^{11)}$. The substrate temperature should be decreased as low as possible in order to suppress the catalytic effects of Co, even for a-C films deposited at low substrate temperatures. 
Recently, we have realized the formation of ultrananocrystalline diamond (UNCD)/nonhydrogenated amorphous carbon composite (UNCD/a-C) films by coaxial arc plasma deposition (CAPD) ${ }^{12,13,14)}$. UNCD/a-C films comprise a large number of diamond grains with diameter of less than $10 \mathrm{~nm}$ and an a-C matrix. CAPD is categorized as physical vapor deposition, and the growth mechanism of diamond grains completely differs from that of CVD, which is mainly employed for the deposition of nanodiamond films. From our previous studies employing optical emission spectroscopic diagnostics of the UNCD/a$\mathrm{C}$ deposition process, it was found that highly energetic carbon species, in particular $\mathrm{C}^{+}$ions, arrive at a substrate in a high density ${ }^{14)}$, which might realize a supersaturated condition for the nucleation of diamond ${ }^{15)}$. The deposition of UNCD/a-C films by CAPD has following distinctive features: i) the formation of UNCD/a-C films does not need the pretreatment of substrates with diamond powder, in other words, the nucleation of diamond spontaneously occurs; ii) hydrogen atmospheres are not necessarily required for the growth, in other words, the film growth is possible at a base pressure; iii) the growth of UNCD grains is possible at low substrate temperatures, even on unheated substrates; and iv) the deposition rate is at least two orders of magnitude larger than that of $\mathrm{CVD}^{16,17)}$. Moreover, UNCD/a-C films are deposited in pulsed arc discharge and the repetition rate of discharge can easily be controlled with an electric circuit. Thus, in order to suppress an increase in the substrate temperature during the deposition, the arc discharge operation can be made at a low repetition rate such as $1 \mathrm{~Hz}$.

In this study, the deposition of UNCD/a-C films by CAPD was carried out on unheated WC-Co substrates, and the availability of the room temperature deposition of UNCD/a-C films by CAPD for hard coating on WC-Co was experimentally investigated. We report that the UNCD/a-C films prepared by CAPD have a high potential for hard coating in terms of materials and deposition process and that the existence of a large number of grain boundaries in the films might release an internal stress in the film.

\section{Experimental Methods}

UNCD/a-C films with a thickness of $2.9 \mu \mathrm{m}$ were deposited on WC-Co substrates (K-type cemented carbide, $\phi 10 \times 4.5 \mathrm{~mm})$ by CAPD with a coaxial arc plasma gun (ULVAC, APG-1000) equipped with a graphite rod (purity of $99.99 \%, \phi 10 \times 30 \mathrm{~mm}$ ). Figure 1 shows the schematic diagram of a preparation apparatus and photograph of arc discharge. Whereas the chemical pretreatment of roughening the WC-Co surface for enhancing the adhesion of the films was made prior to the deposition (the details are confidential), chemical etching for removing Co near the surface was not additionally carried out. The head of the coaxial arc plasma gun was pointed at the WC- Co substrates and the distance between the head of the arc gun and substrate was $15 \mathrm{~mm}$. The inside of a vacuum chamber was evacuated to a base pressure of less than $10^{-4} \mathrm{~Pa}$ by a turbomolecular pump prior to the deposition of films. A voltage of $100 \mathrm{~V}$ was applied to the arc plasma gun equipped with a $720 \mu \mathrm{F}$ capacitor. In order to suppress an increase in the substrate temperature during the deposition, the repetition rate of arc discharges was set to be $1 \mathrm{~Hz}$. The deposition was carried out at the base pressure without inflowing gases. In this condition, the substrate temperature during the deposition was increased to at most $30^{\circ} \mathrm{C}$.

The hardness and Young's modulus of the UNCD/a-C films were measured by nanoindentation. The applied indentation load was $0.5 \mathrm{mN}$. Load-displacement curves by indentation were measured at ten points for each samples for confirming the reproducibility. The internal stress was estimated by measuring the bending deflection of a sample, in which a 134-nm UNCD/a-C film was deposited on a 260 $\mu \mathrm{m}$-thickness $\mathrm{Si}(001)$ substrate with a dimension of $15 \mathrm{~mm}$ $\times 5 \mathrm{~mm}$ at the same preparation condition as the UNCD/aC films deposited on WC-Co substrates by CAPD. The bending deflection curve of the sample was measured along the direction of $\mathrm{Si}[110]$ by a surface roughnessmeter.

The films were crystalline-structurally evaluated by powder. X-ray diffraction (XRD) with $12 \mathrm{keV}$ X-ray from synchrotron radiation at beamline 15 of Kyushu Synchrotron Light Research Center/Saga Light Source. For its measurement, the film was peeled off from the substrate and powdered. The powder was filled in a borosilicate glass capillary with an inside diameter of $0.3 \mathrm{~mm}$. The chemical bonding structure was investigated by X-ray photoemission spectroscopy (XPS) at beamline 12 of Kyushu Synchrotron Light Research Center/Saga Light Source. The $\mathrm{sp}^{3} /\left(\mathrm{sp}^{2}+\mathrm{sp}^{3}\right)$ ratios were estimated from Xray photoemission spectra. The spectra were decomposed

(a)

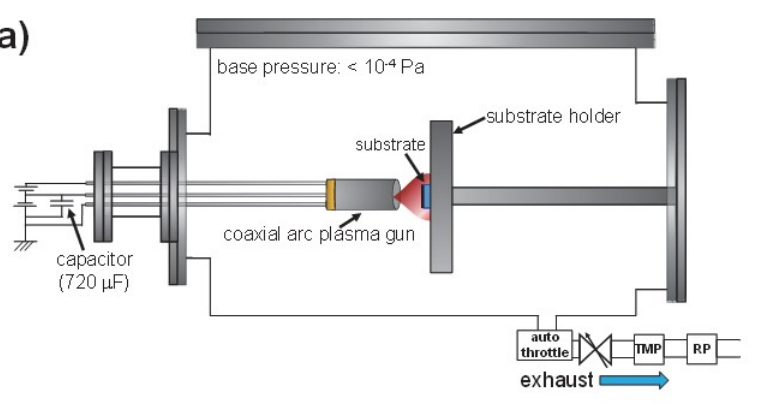

(b)

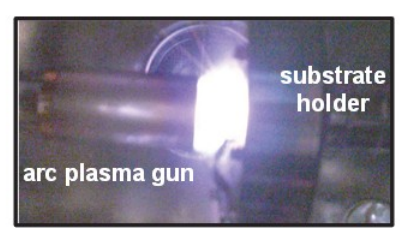

Fig. 1: (a) Schematic diagram of preparation apparatus and (b) photograph of arc discharge. 
into peaks using Voigt function (80\% Gaussian and 20\% Lorentzian) after subtracting the background by Shirley’s method.

\section{Results and Discussion}

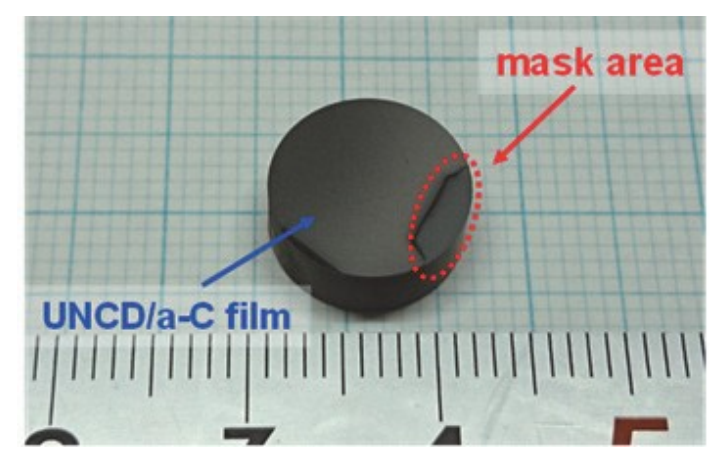

Fig. 2: Optical photograph of UNCD/a-C film deposited on WC-Co substrate.

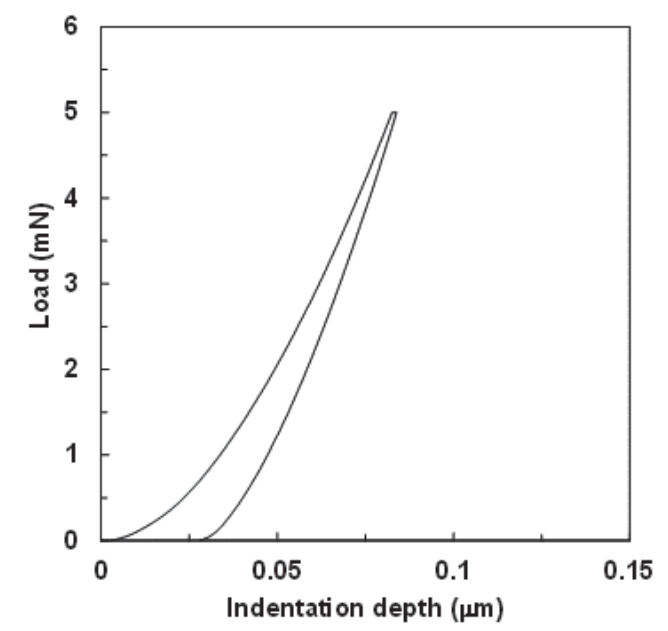

Fig. 3: Load-displacement curve of UNCD/a-C film, measured by nanoindentation.

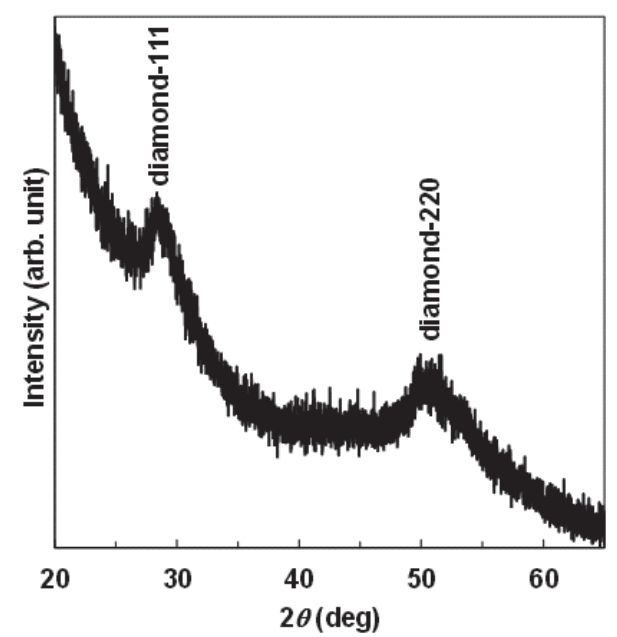

Fig. 4: XRD pattern of UNCD/a-C film that was peeled off from substrate.
Figure 2 shows the optical photograph of an UNCD/a- C film with a thickness of $2.9 \mu \mathrm{m}$ deposited on a WC-Co substrate. The spontaneous peeling off from the substrate was not observed at all. Physical force scratching with a stainless tweezers could not give a damage and cause exfoliation for the film. To estimate the hardness and Young's modulus of the films, load-displacement curves were measured by nanoindentation. Figure 3 shows a typical load-displacement curve of the UNCD/a-C film. The hardness and Young's modulus were calculated to be 51.3 GPa and 520.2 GPa, respectively. These values are larger than those of a-C films deposited on nonbiased substrates and comparable to those of hard a-C films deposited on negatively biased substrates by other methods such as sputtering and FCVA ${ }^{6,8)}$.

One reason for the large values should be owing to a suppression in the graphitization induced by the catalytic effects of Co on WC-Co substrates by realizing the lowtemperature growth by CAPD. The existence of Co atoms in the films could not clearly be detected by energydispersive X-ray (EDX) and secondary ion mass spectroscopic measurements. The diffusion of Co atom from the WC-Co substrates into the films hardly occurs during the deposition. Another reason is that the pulsed deposition with highly energetic atomic species in a high density in CAPD should be advantageous for forming $\mathrm{sp}^{3}$ bonds including diamond nuclei ${ }^{14,18)}$.

To confirm the existence of diamond grains in the films, XRD measurements with synchrotron radiation were examined. Figure 4 shows the typical XRD pattern, which was transformed from Debye-Scherer rings recorded on an imaging plate. Diffraction peaks due to diamond-111 and 220 are observed. They are extremely broad, which indicates that the size of UNCD grains is extremely small. The grain size was estimated to be approximately $2.4 \mathrm{~nm}$ by Scherrer equation ${ }^{19)}$. There are no peaks due to graphite, which implies that graphite used as a carbon source is

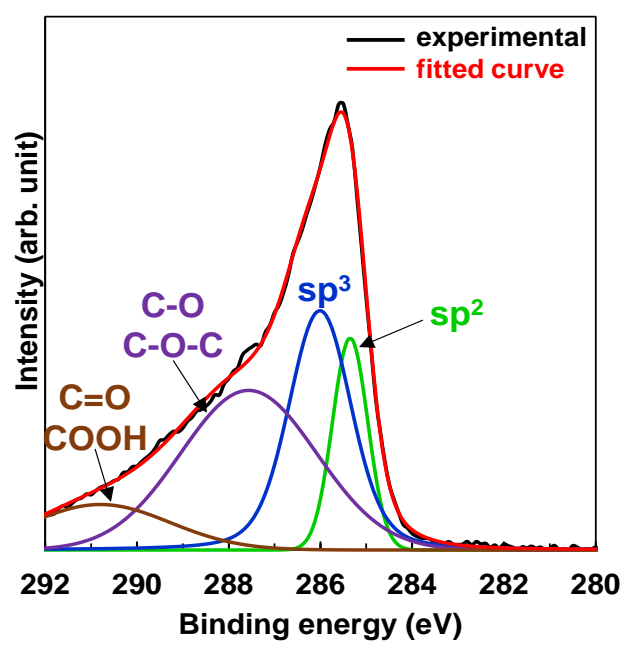

Fig. 5: C 1s X-ray photoemission spectra of UNCD/a-C film. 
Table 1: Comparison in hardness and internal stress between UNCD/a-C and a-C films.

\begin{tabular}{ccccc}
\hline & D. Sheeja et al. & Y. B. Zhang et al. & H. J. Scheibe et al. & our data \\
\hline Film type & a-C & a-C & a-C & UNCD/a-C \\
\hline Hardness $(\mathrm{GPa})$ & 52.0 & 51.0 & 45.0 & 51.3 \\
\hline Stress type & Compressive & Compressive & Compressive & Compressive \\
\hline Stress value $(\mathrm{GPa})$ & 10.1 & 7.5 & 5.0 & 4.5 \\
\hline Ref. No. & 26 & 23 & 25 & - \\
\hline
\end{tabular}

almost decomposed into atomic species by arc discharge. The graphitization of UNCD grains hardly occurs on the untreated WC-Co substrate since the UNCD grain size is comparable with that of UNCD/a-C films deposited on other substrates.

The $\mathrm{sp}^{3} /\left(\mathrm{sp}^{2}+\mathrm{sp}^{3}\right)$ ratio was estimated from the X-ray photoemission spectra of the films. The typical $\mathrm{C} 1 \mathrm{~s}$ photoemission spectrum is shown in Fig. 5. The spectrum is decomposed into the following four peaks: $\mathrm{sp}^{2}$-bonded carbon, $\mathrm{sp}^{3}$-bonded carbon, carbon-oxygen single bond (C$\mathrm{O}$ and $\mathrm{C}-\mathrm{O}-\mathrm{C})$, and carbon-oxygen double bond $(\mathrm{COOH}$ and $\mathrm{C}=\mathrm{O})^{20 \text { ) }}$. The carbon-oxygen peaks should be due to adsorbed oxygen on the film surface according to our previous research ${ }^{21)}$. The $\mathrm{sp}^{3} /\left(\mathrm{sp}^{2}+\mathrm{sp}^{3}\right)$ ratio was estimated to be approximately $68.9 \%$, from the areas of $\mathrm{sp}^{2}$ and $\mathrm{sp}^{3}$ peaks ${ }^{22}$. Since this value is comparable with that of UNCD/a-C films deposited on Si substrates, the graphitization by the Co catalytic effects hardly occurs.

Figure 6 shows the bending deflection curve of the sample comprising the 100-nm UNCD/a-C film and 100$\mu \mathrm{m}$ Si (100) substrate. For a sample wherein a film exits on a substrate, in the case of the sample bending being convex and concave, the internal stress of the film is compressive and tension, respectively. Since the measured profile is convex as shown in Fig. 6, the internal stress in the film is compressive, which is the same as results on hard a-C films reported thus far $9,23,24,25,26)$.

The internal stress $\sigma$ was estimated to be $4.5 \mathrm{GPa}$ by using the following Stoney's Formula for long and narrow samples ${ }^{27)}$.

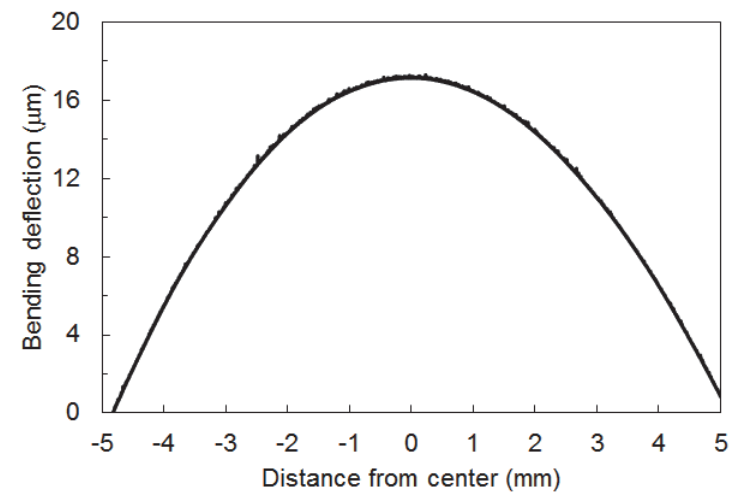

Fig. 6: Bending deflection curve of UNCD/a-C film with thickness of $100 \mathrm{~nm}$ deposited on $100-\mu \mathrm{m}$ Si (100) substrate, measured by surface roughnessmeter.

$$
\sigma=\frac{E_{s} t_{s}}{3\left(1-v_{s}\right) R t_{f}}
$$

Here, $E_{\mathrm{s}}, t_{\mathrm{s}}$, and $v_{\mathrm{s}}$ are the Young's modules, thickness, and Poisson's ratio of a substrate, respectively, and $R$ and $t_{\mathrm{f}}$ are the radius of curvature and film thickness. The internal stress value is small as compared with comparably hard a$\mathrm{C}_{\text {films }}{ }^{23)}$. Table 1 shows a comparison in the hardness and internal stress between UNCD/a-C and hard a-C films ${ }^{23,25,26)}$. The internal stress is compressive for all. The internal stress of the UNCD/a-C film is much smaller than those of comparably hard a-C films with hardness of larger than $50 \mathrm{GPa}$. As compared to $45 \mathrm{GPa}$ hardness a-C film, the internal stress is smaller.

Whereas the upper limit of the thickness for hard a-C films is a few hundred nanometers, UNCD/a-C films can be grown at thicknesses of approximately $3 \mu \mathrm{m}$, as experimentally demonstrated in this study. The small internal stress is a reason for it. We consider that a large number of grain boundaries (GBs) might effectively release the internal stress of the films somehow ${ }^{28)}$, since the existence of a huge number of GBs in the film is specific to UNCD/a-C films. Here, GBs denote interfaces between UNCD grains and those between UNCD grains and an a-C matrix.

\section{Conclusion}

UNCD/a-C films with the hardness of $51 \mathrm{GPa}$ and the Young's modulus of $520.2 \mathrm{GPa}$ were grown on WC-Co substrates at room temperature by CAPD without negatively biasing the substrates. The low temperature growth can suppress the graphitization induced by the catalytic effects of Co on the WC-Co substrates. The internal compress-stress of the 51.3-GPa hardness film is approximately $4.5 \mathrm{GPa}$, which is evidently smaller than that of comparably hard a-C films. This should be because a huge number of GBs that is structurally specific to UNCD/a-C films probably have a role of releasing the internal stress of UNCD/a-C films. It was experimentally demonstrated that UNCD/a-C is a new hard coating substance and CAPD is a novel technique for the deposition of UNCD/a-C films.

\section{Acknowledgements}

This research was partially financially supported by Osawa Scientific Studies Grants Foundation, JSPS KAKENHI Grant-in-Aid for JSPS Fellows (Grant No. 
15J00654), Grant-in-Aid for Young Scientists (B) (Grant No. 26790019), and JST A-STEP (Grant No. AS2511118M). The experiment using synchrotron radiation was performed at SAGA-LS with the approval of the Kyushu Synchrotron Light Research Center (Proposal No. 1505044S/BL15 and 1410105S/BL12).

\section{References}

1) R. Polini, Thin Solid Films, 515, 4 (2006).

2) R. Polini, M. Barletta, and G. Cristofanilli, Thin Solid Films, 519, 1629 (2010).

3) H. Gomez, D. Durham, X. Xiao, M. Lukitsch, P. Lu, K. Chou, A. Sachdev, and A. Kumar, Mat. Proc. Technol., 212, 523 (2012).

4) S. Söderberg, A. Gerendas, and M. Sjöstrand, Vacuum, 41, 1717 (1990).

5) X. Chen and J. Narayam, J. Appl. Phys., 74, 4168 (1993).

6) S. Lee, D. G. Kim, and J. K. Kim, Tribology Online, 7, 201 (2012).

7) N. A. Sánchez, C. Rincón, G. Zambrano, H. Galindo, and P. Prieto, Thin Solid Films, 373, 247 (2000).

8) D. Sheeja, B. K. Tay, L. J. Yu, S. P. Lau, J. Y. Sze, and C. K. Cheong, Thin Solid Films, 420-421, 62-69 (2002).

9) P. J. Fallon, V. S. Veerasamy, C. A. Davis, J. Robertson, G. A. J. Amaratunga, W. I. Milne, and J. Koskinen, Phys. Rev. B, 48, 4777 (1993).

10) L. Dignard-Baile, M. L. Trudeau, A. Joly, R. Schulz, G. Lalande, D. Guay, and J. P. Dodelet, J. Mat. Res., 9, 3203 (1994).

11) Z. W. Xie, L. P. Wang, X. F. Wang, L. Huang, Y. Lu, and J. C. Yan, Appl. Surf. Sci., 258, 1206 (2011).

12) T. Yoshitake, Y. Nakagawa, A. Nagano, R. Ohtani, H. Setoyama, E. Kobayashi, K. Sumitani, Y. Agawa, and K Nagayama, Jpn. J. Appl. Phys., 49, 015503 (2010).

13) K. Hanada, T. Nishiyama, T. Yoshitake, and K. Nagayama, Diam. Relat. Mat., 19, 899 (2010).

14) K. Hanada, T. Yoshida, Y. Nakagawa, and T. Yoshitake, Jpn. J. Appl. Phys., 49, 125503 (2010).

15) W. Kulisch, Deposition of Diamond-Like Superhard Materials, edited by G. Höhler, Vol. 157, pp. 125-171 (Springer, Berlin, 1999).

16) X. Xiao, J. Birrell, and J. Gerbi, J. Appl. Phys., 96, 2232 (1993).
17) C. Popov, W. Kulisch, S. Boycheva, K. Yamamoto, G. Ceccone, and Y. Koga, Diam. Relat. Mat., 13, 2071 (2004).

18) Y. Katamune, H. Naragino, K. Hanada, A. Tominaga, and T. Yoshitake, New Diamond, 116, Vol. 31, No. 1 (2015) pp. 8-12.

19) A. L. Patterson, Phys. Rev., 56, 978 (1939)

20) D. Ballutau, N. Simon, H. Girard, E. Rzepka, and B. Bouchet-Fabre, Diam. Relat. Mat., 15, 716 (2006).

21) S. Ohmagari, T. Yoshitake, A. Nagano, R. Ohtani, H. Setoyama, E. Kobayashi, and K. Nagayama, Diam. Relat. Mat., 19, 911 (2010).

22) S. Al-Riyami, S. Ohmagari, and T. Yoshitake, Diam. Relat. Mat., 19, 510 (2010).

23) Y. B. Zhang, S. P. Lau, D. Sheeja, and B. K. Tay, Surf. Coat. Tech., 195, 338 (2005).

24) D. R. McKenzie, D. Muller, B. A. Pailthorpe, Z. H. Wang, E. Kravtchinskaia, D. Segal, P. B. Lukins, P. J. Martin, G. Amaratunga, P. H. Gaskell, and A. Saeed, Diam. Relat. Mat., 1, 51 (1991).

25) H. J. Scheibe and B. Schultrich, Thin Solid Films, 246, 92 (1994).

26) D. Sheeja, B. K. Tay, S. P. Lau, and X. Shi, Wear, 249, 433 (2001).

27) D. W. Hoffman, Phys. Thin Films, 3, 211 (1966).

28) M.G. Fyta, G. C. Hadjisavvas, and P. C. Kelires, Diam. Relat. Mat., 16, 1643 (2007). 